Journal of Advanced Research in Fluid Mechanics and Thermal Sciences

Journal homepage: www.akademiabaru.com/arfmts.html ISSN: 2289-7879

\title{
Void Fraction and Flow Pattern of R-290 in A Horizontal Evaporator: Effects of Pipe Diameter and Cooling Capacity
}

\author{
Apip Badarudin ${ }^{1}$, Andriyanto Setyawan $^{1,},{ }^{*}$ Windy Hermawan Mitrakusuma ${ }^{1}$ \\ 1 Department of Refrigeration and Air Conditioning Engineering, Politeknik Negeri Bandung, Bandung 40012, Indonesia
}

\section{\begin{tabular}{l} 
ARTICLE INFO ABSTRACT \\
\hline
\end{tabular}}

\section{Article history:}

Received 3 March 2021

Received in revised form 28 April 2021

Accepted 10 May 2021

Available online 28 July 2021

Keywords:

R-290; void fraction; flow pattern; air conditioning; evaporator

\begin{abstract}
Void fraction and flow pattern play important roles in the performance of evaporator in an air conditioning system. In this paper, the behaviors of void fraction and flow pattern of refrigerant R-290 in a horizontal evaporator are discussed. To simplify the analysis, the evaporator was divided into 10 segments. The void fraction was calculated based on the refrigerant flow quality and the flow pattern was determined on the basis of superficial gas and liquid velocity plotted in the flow pattern map. The calculation was carried on air conditioning machines with nominal capacities of $2.64 \mathrm{~kW}, 3.62 \mathrm{~kW}$, and $5.28 \mathrm{~kW}$ using the evaporator pipe diameters of 3/8 in and 5/16 in. Generally, the lower evaporating temperature results in the higher void fraction, higher gas superficial velocity, and lower liquid superficial velocity. For all ranges of evaporator diameter and cooling capacity, annular flow is found to be the dominant flow pattern. The wavy flow is only found in the lower cooling capacity and larger evaporator diameter. Meanwhile, the slug flow occupies $16.7 \%$ to $25.8 \%$ of evaporator segment.
\end{abstract}

\section{Introduction}

In an air conditioning machine that employs vapor-compression refrigeration system, the evaporator absorbs heat from the surrounding. The absorbed heat is then used to evaporate the refrigerant that flows within the evaporator pipe. In an ideal evaporator, the temperature of refrigerant along the pipe is constant along the pipe due to the heat equilibrium of the absorbed heat and the latent heat of evaporation of refrigerant. When travels in the evaporator, the void fraction or the gas fraction of the refrigerant changes along the evaporator tube. In two-phase flow employing gas and liquid, the void fraction or gas fraction represents the ratio of pipe cross-sectional area filled by gas to the total area of the pipe. It has a close relationship to the flow pattern of refrigerant.

Correlations for predicting the void fraction have been extensively developed for the last four decades. The correlations could be developed on the basis of flow quality [1-4]. Other correlations could be developed by utilizing the superficial gas and liquid velocity, liquid Reynolds number, fluid properties, system pressure, and flow conditions [5-7]. Other model for void fraction prediction for

\footnotetext{
* Corresponding author.

E-mail address: andriyanto@polban.ac.id
}

https://doi.org/10.37934/arfmts.85.1.4053 
air conditioning with R410A has been experimentally studied [8]. In addition, a simplified correlation for predicting the liquid holdup - as a complement of void fraction - has also been proposed [9].

Many kinds of flow pattern are generally found in evaporator: annular, dispersed, intermittent, slug/plug, and bubble flow. The flow pattern of annular, dispersed, intermittent, and stratified were reported in experiments by using air-water mixture, R410A, and R134a in 6 and 14-port microchannel heat exchangers with hydraulic diameter of $1.54 \mathrm{~mm}$ and $1.02 \mathrm{~mm}$ [10]. The mass flux for this experiment ranges from 50 to $300 \mathrm{~kg} / \mathrm{s} . \mathrm{m}^{2}$. It is also reported that under constant flow quality and mass flux, different flow configurations occur at once in different tubes.

The flow patterns of bubble, slug/plug, and annular flow were reported in microchannel [11]. These patterns were observed in a visualization experiment with R134a in $92 \times 952$ micrometers of rectangular channel. The experiment was performed under vapor quality of 0.05-0.95 and mass flux of $279-461 \mathrm{~kg} / \mathrm{s} . \mathrm{m}^{2}$. The same flow patterns were also reported in visualization experiment using horizontal small channels of 1.03 to $3.04 \mathrm{~mm}$ diameter with three different refrigerants: R134a, R236fa, and R245fa [12]. A parameter called confinement number, $C_{0}$, was used in this experiment. It is proportional to the square root of surface tension and inversely proportional to channel diameter and square root of gravity acceleration and density difference between liquid and gas. The gravity effect was fully compensated by the shear stress and surface tension when the confinement number, Co, approaches 1 . In other words, a symmetry annular flow was formed when $\mathrm{Co} \approx 1$.

Annular, stratified, intermittent, and stratified-wavy flow were found in a visualization experiment using refrigerant ammonia in a $15.86 \mathrm{~mm}$ OD stainless steel tube [13]. The test was conducted with refrigerant mass fluxes from 10 to $140 \mathrm{~kg} / \mathrm{s} . \mathrm{m}^{2}$. The driving forces for each flow pattern were described in this report.

By using R134a, flow patterns of bubble, elongated bubble, and annular were reported in visualization experiment of upward vertical flow in microchannel evaporator [14]. As the heat is added to the evaporator, the length of bubble increases and an elongated bubble is formed. The annular flow was formed when the liquid between two elongated bubbles collapses.

Bubby-slug, churn, and annular flow patterns have been observed by using visualization experiment in a microchannel heat exchanger using R134a and PAG46 oil [15]. An occasional flow reversal has also been noticed when the flow pattern is bubbly/slug transition. It is likely due to the higher flow resistance in the upstream as the refrigerant was fed in two-phase.

Later, a study of R32 flow pattern was performed in a microchannel with a diameter of 643 microns and mass flux of $50-300 \mathrm{~kg} / \mathrm{kg} / \mathrm{s} \cdot \mathrm{m}^{2}$ [16]. A slug/plug flow was obtained at mass flux of 50 $\mathrm{kg} / \mathrm{s} \cdot \mathrm{m}^{2}$. The annular flow was formed when the mass flux was increased to $100 \mathrm{~kg} / \mathrm{kg} / \mathrm{s} . \mathrm{m}^{2}$. Transitional flow was found at mass flux of $150 \mathrm{~kg} / \mathrm{kg} / \mathrm{s} \cdot \mathrm{m}^{2}$.

The effects of inlet air temperature in the R22 evaporator, refrigerant flowrate, and evaporation pressure on the flow pattern in horizontal pipe with a length of $20 \mathrm{~m}$ have been examined [17]. For low refrigerant flow rate, the flow pattern is dominated by annular flow, with intermittent flow is found near the pipe entry and superheat is found near the pipe exit. For high refrigerant flow rate, the intermittent flow vanishes and replaced by annular, in which the gas flows in the pipe centre while liquid refrigerant flows in the pipe wall. In this flow, the ring form of liquid could have an asymmetry of liquid thickness [18]. For different air inlet temperature from 300 to $305 \mathrm{~K}$, it was reported that the flow pattern is all annular. For all range of evaporating pressure, annular flow dominates the flow pattern. However, intermittent flow was reported in a small segment near the pipe inlet for high evaporating pressure.

The influence of flow quality on the void fraction and flow regime has been studied by visual experiment in $7 \mathrm{~mm}$ pipe using R134a as working fluid [19]. High void fraction was reported for experiment with high flow quality. Slug and stratified flow are found for low refrigerant flow quality 
and low mass flux. On the other hand, annular flow is found for high flow quality and high mass flux. The effects of the mass quality and heat flux on the heat transfer coefficient has also been examined by Akbar et al., [20]. In their experiment, the heat transfer increases as the mass quality increases. However, it decreases when the mass quality is in the range of 0.7 to 1 .

Hitherto, there is no report concerning to the flow pattern and void fraction of R290 in horizontal evaporator. In this study, the behavior of the void fraction and flow pattern in a horizontal-straight evaporator with this kind of refrigerant is elaborated. Examination on the effect of evaporator segment length on the refrigerant vapor quality and void fraction are discussed first. The effects of the evaporator pipe axial position on the refrigerant superficial vapor and liquid velocity were also discussed. In addition, the effects of evaporator pipe diameter and cooling capacity on the flow pattern are also presented.

\section{Methodology}

In a vapor compression refrigeration system, as commonly found in a split-type air conditioning, the following processes take place: compression, condensation, expansion, and evaporation. In pressure-enthalpy chart, the processes are expressed by line 1-2, 2-3, 3-4, and 4-1, respectively. In the evaporator, the mixture of liquid and vapor refrigerant enters with a certain vapor quality, $x$. When the evaporator absorbs heat from the surrounding space, the refrigerant inside the evaporator boils. It increases the vapor quality of refrigerant. At the end of the evaporator pipe, the entire refrigerant is in the vapor state and the value of $x$ is 1 . The illustration of the vapor fraction of refrigerant in the evaporator pipe is shown by line 4-1 in Figure 1.

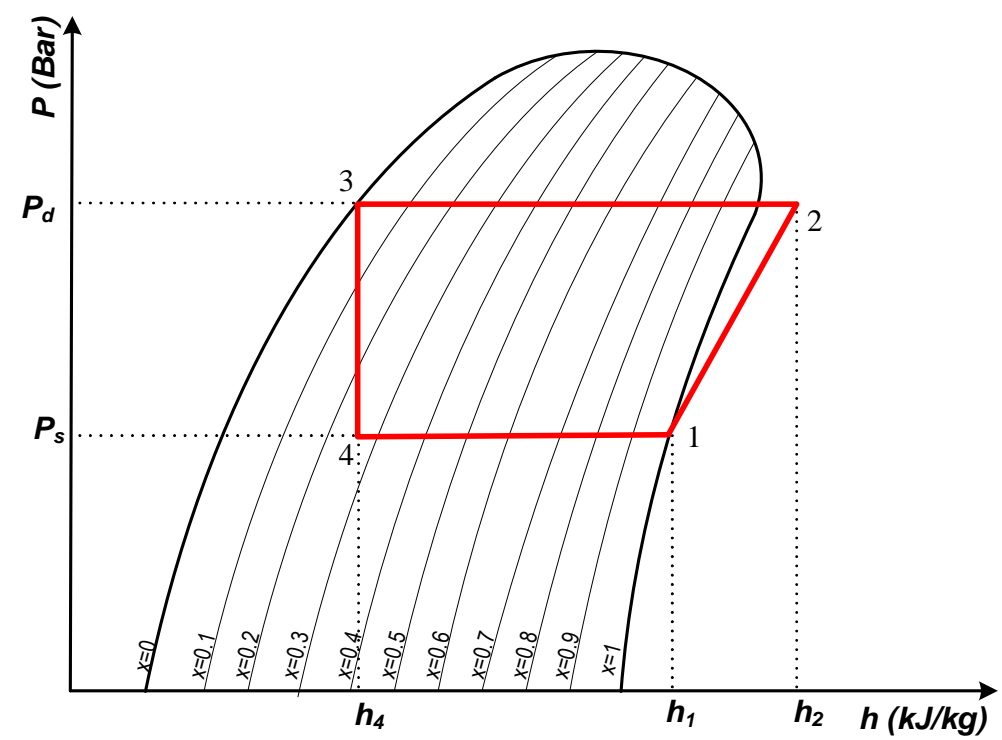

Fig. 1. Illustration of vapor fraction of refrigerant in the evaporator pipe

In this study, the behavior of void fraction and flow pattern along evaporator pipe were examined. For simplification of the study, the evaporator pipe is assumed to be horizontal and straight. To obtain the void fraction as a function of the length of evaporator segment, the vapor quality as function of evaporator segment length was determined first. In this case, the total length of the evaporator is denoted as $L$. To simplify the analysis, the evaporator is divided by 10 segments from $s / L=0,0.1,0.2, \ldots, s / L=1$. Assuming a constant pressure and rate of evaporation of refrigerant in the horizontal tube evaporator, the properties of refrigerant along the segment of evaporator can 
be determined by using the Refprop software from NIST. As an illustration, for a split air conditioner with a capacity of $2.64 \mathrm{~kW}$ under ideal condition, the refrigerant from the capillary tube enters the evaporator coil $(s / L=0)$ at the vapor mass quality of 0.246 . It means that $24.6 \%$ mass of the refrigerant is in vapor phase. At the exit end of evaporator (or $s / L=1$ ), the vapor mass quality is 1 and the other properties in between could be determined easily. As a result, the vapor quality as function of evaporator segment length can be derived.

\subsection{Determining the Void Fraction}

The void fraction, or the ratio of the volume of refrigerant in vapor phase to the total volume at this point, is determined by

$\alpha=\frac{\text { Volume of pipe segment occupied by vapor phase }}{\text { Total volume of pipe segment }}$

For a certain segment of pipe, the void fraction can be expressed as

$\alpha=\frac{\text { Area of pipe occupied by vapor phase }}{\text { Area of pipe }}$

The volume of vapor phase in the evaporator pipe is calculated by multiplying the vapor quality with its specific volume $\left(v_{G}\right)$, or

$V_{G}=x * v_{G}$

Similarly, the volume of liquid phase is calculated by multiplying the liquid quality $1-x)$ with its specific volume $\left(v_{L}\right)$, or

$V_{L}=(1-x) * v_{L}$

From which, the void fraction can be calculated as

$\alpha=\frac{V_{G}}{V_{G}+V_{L}}=\frac{x * v_{G}}{\left(x * v_{G}\right)+(1-x) * v_{L}}$

By which the void fraction distribution as a function of evaporator segment length can be determined. In two-phase flow, void fraction is a complement of liquid holdup. Therefore, once the void fraction is determined, the liquid holdup can be obtained [21].

\subsection{Determining the Vapor and Liquid Refrigerant Superficial Velocity}

Although the cooling capacity of a refrigeration or air conditioning machine varies in accordance to the operating condition, the swept volume of the compressor is constant, independent of its operating condition as long as the compressor speed is constant. Once the capacity of the compressor is obtained, the swept volume $(Q)$ could be determined. By using the swept volume, the refrigerant mass flow rate could be calculated as

$\dot{m}=Q \rho$ 
where $\dot{m}$ is the total mass flow rate and $\rho$ is the refrigerant density. In the evaporator, the refrigerant could be found in liquid phase and vapor phase. The mass flow rate of both phases is expressed as

$\dot{m}_{G}=Q \rho x$

$\dot{m}_{L}=Q \rho(1-x)$

where $\dot{m}_{G}$ and $\dot{m}_{L}$ are refrigerant mass flow rate in vapor and liquid phase, respectively. The vapor quality, $x$, is defined as the ratio of mass fraction of vapor refrigerant to the total refrigerant mass. The value of $x$ varies with the axial position in the evaporator pipe, from 0 to 1 . At the evaporator inlet, the value of $x$ is small, as most of the refrigerant is in liquid phase. At the evaporator outlet, ideally all refrigerant is in vapor phase $(x=1)$ to avoid liquid slugging in the compressor. In this method, the evaporator pipe is assumed to be straight and horizontal from the inlet through the outlet. Using the last two equations, the superficial vapor and liquid velocity are calculated as

$J_{G}=\frac{\dot{m}_{G}}{0.25 \pi D^{2} \rho_{G}}$

$J_{L}=\frac{\dot{m}_{L}}{0.25 \pi D^{2} \rho_{L}}$

where $D$ is the inner diameter of the evaporator pipe. $J_{G}$ and $J_{L}$ denote the superficial velocity of vapor and liquid refrigerant, respectively. The last two parameters are defined as the velocity of the vapor and liquid assuming the single phase of fluid flows in the pipe.

\subsection{Determining the Flow Pattern}

The flow pattern of the refrigerant flowing in the horizontal evaporator tube can be determined by plotting the corresponding superficial gas and liquid velocity of the refrigerant in the Mandhane Map [22]. In this method, the flow pattern can be determined both manually by visual inspection of the chart and analytically by employing correlations in the transitions of flow pattern in the Mandhane Map. For the transition of plug/slug to annular flow pattern, the transition can be approximately expressed as

$J_{L}=-0.147 \ln \left(J_{G}\right)+0.4555$ for $J_{L}<0.1 \mathrm{~m} / \mathrm{s}$

Meanwhile, the boundary of transition of stratified-wavy flow and annular flow is expressed as

$J_{L}=9 \times 10^{-6} J_{G}^{3}-0.0001 J_{G}^{2}+0.0269 J_{G}-0.0269$ for $J_{L} \leq 0.1 \mathrm{~m} / \mathrm{s}$

The correlations of Eq. (11) and Eq. (12) have correlation coefficients of 0.98 and 1, respectively. Once the $J_{G}$ and $J_{L}$ of the flow of refrigerant in evaporator pipe obtained, the flow pattern of the refrigerant in the evaporator can be defined [23]. In this method, three nominal capacities of split air conditioner are used, i.e., $2.49 \mathrm{~kW}, 3.52 \mathrm{~kW}$, and $5.28 \mathrm{~kW}$ (or $9000 \mathrm{Btu} / \mathrm{h}, 12000 \mathrm{Btu} / \mathrm{h}$, and 18000 Btu/h). Two variations of pipe size with inner diameter of $6.3 \mathrm{~mm}$ and $7.9 \mathrm{~mm}$ are employed. The analysis of flow pattern in this study was based on ideal refrigeration cycle or sometimes referred as basic cycle [24]. In this case, no superheat nor subcooling of refrigerant were assumed in the evaporator and condenser outlet. 


\section{Results and Discussion}

In this section, the refrigerant vapor quality is discussed first. As the vapor quality is obtained, the void fraction can be determined. The results are then used for calculating the superficial velocity of vapor and liquid. Finally, the flow patterns can be determined by using the vapor and liquid superficial velocity.

\subsection{Refrigerant Vapor Quality and Void Fraction}

During travels in the evaporator pipe, the refrigerant vaporizes due to the load from the surrounding. The evaporation increases the vapor fraction $x$ and at the evaporator outlet, all refrigerant is in vapor phase $(x=1)$. Due to the evaporation of refrigerant, the superficial velocity of vapor along the pipe increases, while the superficial velocity of liquid decreases.

Refrigerant from the capillary tube enters the evaporator $(s / L=0)$ at a certain value of vapor quality $(x)$, dependent of the operating condition. For ideal operation of refrigeration system in a split $A C$, the refrigerant at the evaporator outlet $(s / L=1)$ is in saturated vapor phase. As an illustration, for cooling capacity of $5.28 \mathrm{~kW}$ at $s / L=0$, the quality of vapor refrigerant is 0.246 for evaporator temperature setting of $5^{\circ} \mathrm{C}$. The vapor quality increases to 0.281 and 0.307 when the evaporating temperature decreases to $0^{\circ} \mathrm{C}$ and $-5^{\circ} \mathrm{C}$, respectively. Further decrease of evaporating temperature to $-10^{\circ} \mathrm{C},-15^{\circ} \mathrm{C}$, and $-20^{\circ} \mathrm{C}$ results in the increase of vapor quality to $0.334,0.358$, and 0.384 , respectively. The vapor quality of refrigerant at the other axial positions of pipe segment is shown in Figure 2. As the refrigerant travels from $s / L=0$ (at the evaporator inlet) to $s / L=1$ (at the evaporator outlet), the vapor fraction increases linearly until reaches the maximum value of $x=1$, where all refrigerant is in the vapor phase. The value of $x$ was resulted from the calculation using REFPROP Software from NIST (National Institute of Standards and Technology). With the constant cooling load, the evaporation rate of refrigerant is also constant. It results in the constant increase of vapor fraction with the axial position of evaporator.

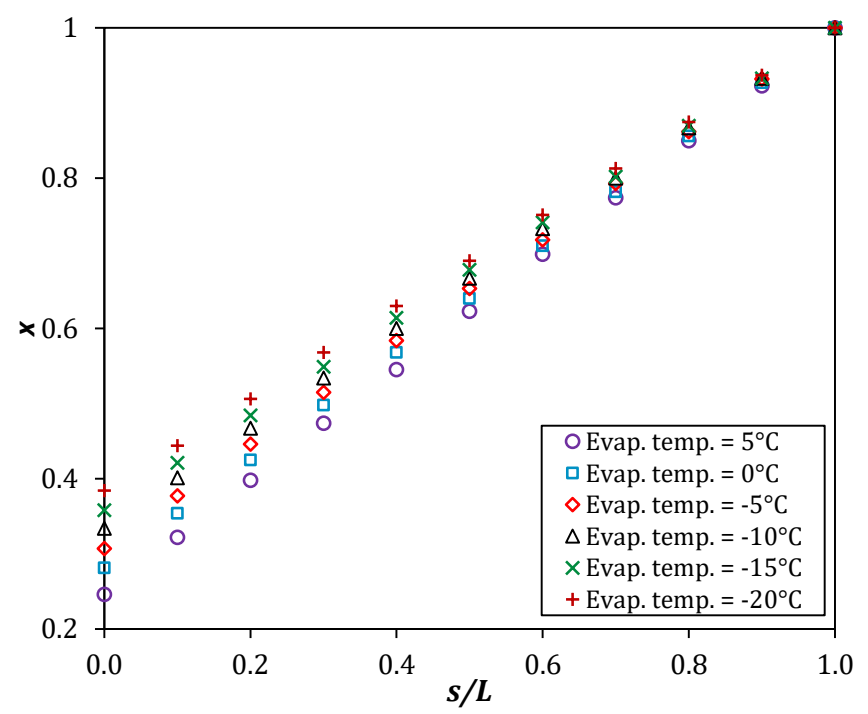

Fig. 2. Effect of axial position at evaporator pipe $(s / L)$ on vapor quality for nominal cooling capacity of 5.28 $\mathrm{kW}$ and nominal pipe size $5 / 16$ in 
The effect of the evaporator segment length on the void fraction at different evaporating temperature is presented in Figure 3. As can be seen, the void fraction is 1 at the evaporator outlet $(s / L=1)$. In general, the void fraction increases as the refrigerant travels from $s / L=0$ to $s / L=1$. As the void fraction $(\alpha)$ is calculated on the basis of phase volume instead of phase mass as in vapor fraction $(x)$, the value of $\alpha$ is generally higher than that of $x$. The similar results have also been reported [8]. It is also obvious that the lower evaporating temperature provides the higher void fraction. As an illustration, at the evaporator inlet, the void fraction is 0.932 for evaporating temperature of $+5^{\circ} \mathrm{C}$. The void fraction increases to 0.952 for evaporating temperature of $0^{\circ} \mathrm{C}$ and 0.984 for evaporating temperature of $-20^{\circ} \mathrm{C}$. This phenomenon is mainly caused by the lower density (or higher specific volume) when the evaporator temperature drops.

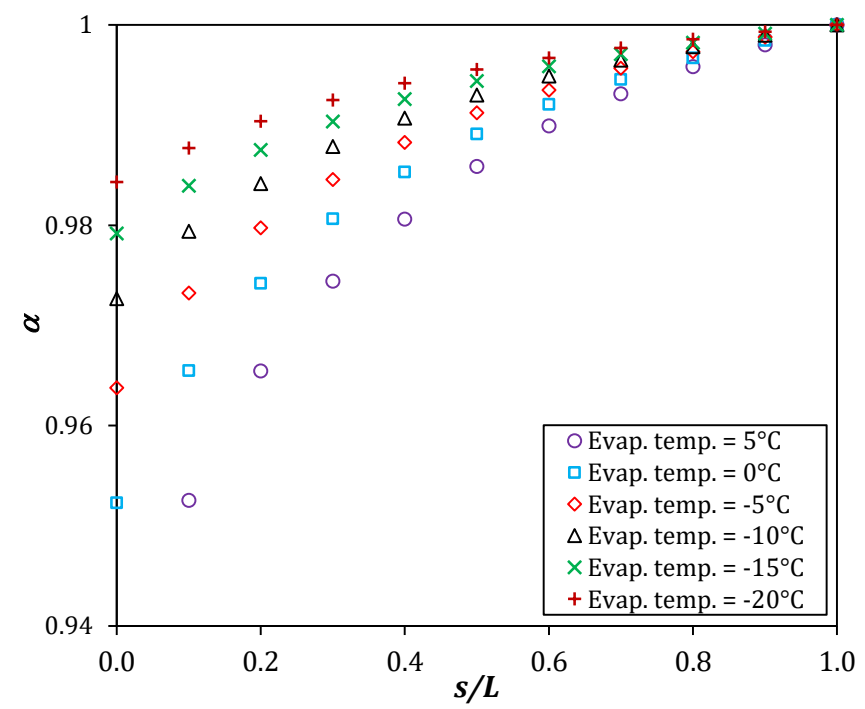

Fig. 3. Effect of axial position at evaporator pipe $(s / L)$ on void fraction for nominal cooling capacity of 5.28 kW and nominal pipe size 5/16 in

\subsection{Vapor and Liquid Superficial Velocity}

Due to the increase of the void fraction of refrigerant as it travels along evaporator pipe, the velocity of vapor refrigerant also increases. As a result, the superficial velocity of vapor refrigerant $\left(J_{G}\right)$ also increases. As could be seen in Figure 4, for evaporating temperature of $5^{\circ} \mathrm{C}$ the superficial vapor velocity increases linearly from $s / L=0$ to $s / L=1$, ranges from $5.76 \mathrm{~m} / \mathrm{s}$ to $23.6 \mathrm{~m} / \mathrm{s}$. Detailed examination of this figure reveals that the higher superficial velocity is resulted for the lower evaporating temperature. At the evaporator outlet, however, the superficial velocity of vapor refrigerant is equal even though the evaporating temperature is different. This is mainly due to the equal swept volume of the compressor used in the air conditioning machine and all refrigerant is in the vapor phase.

Apart from superficial vapor velocity, the superficial liquid velocity $\left(J_{L}\right)$ decreases as the refrigerant travels from the inlet to the outlet of the evaporator. This is mainly due to the reduced amount of liquid refrigerant when it travels along the evaporator pipe. For the cooling capacity of $5.28 \mathrm{~kW}$, at the inlet of evaporator the superficial liquid velocity ranges from $0.31 \mathrm{~m} / \mathrm{s}$ to $0.89 \mathrm{~m} / \mathrm{s}$. Examination of Figure 5 reveals that the superficial liquid velocity decreases as the evaporating temperature decreases. In addition, the superficial liquid velocity at the evaporator outlet is 0 because no liquid refrigerant remained, and all refrigerant is in the vapor phase. Along the evaporator, the evaporation rate of the refrigerant is likely to be linear function of evaporator 
segment length $(s / L)$. The behavior of superficial liquid velocity is similar for different evaporator pipe diameter, except that the value of the velocity is somewhat different. If the pipe diameter is larger, the superficial velocity will be smaller. As an example, for evaporator pipe diameter of $3 / 8$ inch, the value of $J_{L}$ at the evaporator inlet ranges from $0.19 \mathrm{~m} / \mathrm{s}$ to $0.57 \mathrm{~m} / \mathrm{s}$ for evaporating temperature of $-20^{\circ} \mathrm{C}$ to $5^{\circ} \mathrm{C}$.

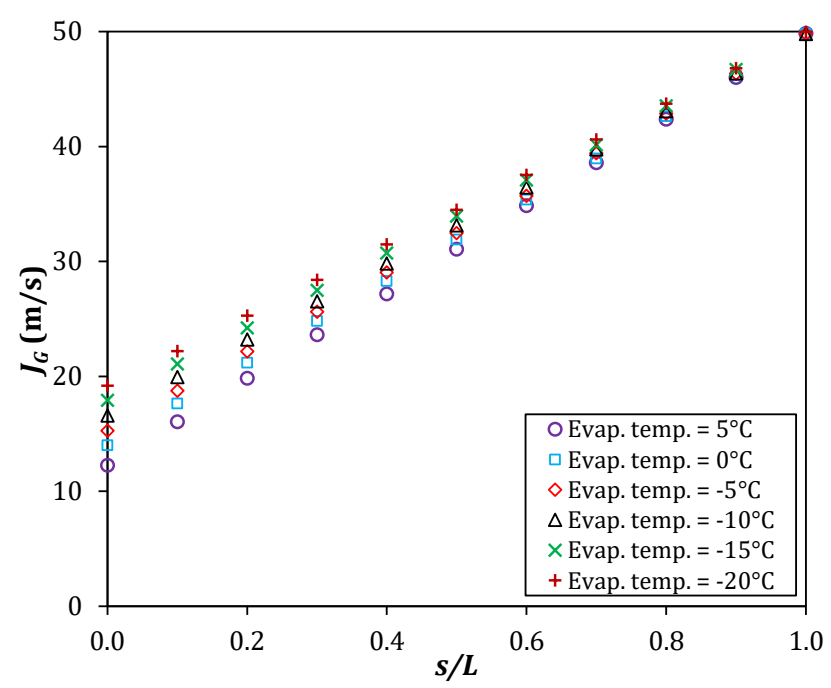

Fig. 4. Effect of axial position at evaporator pipe $(s / L)$ on superficial gas velocity (cooling capacity $5.28 \mathrm{~kW}$ and pipe diameter $5 / 16$ in)

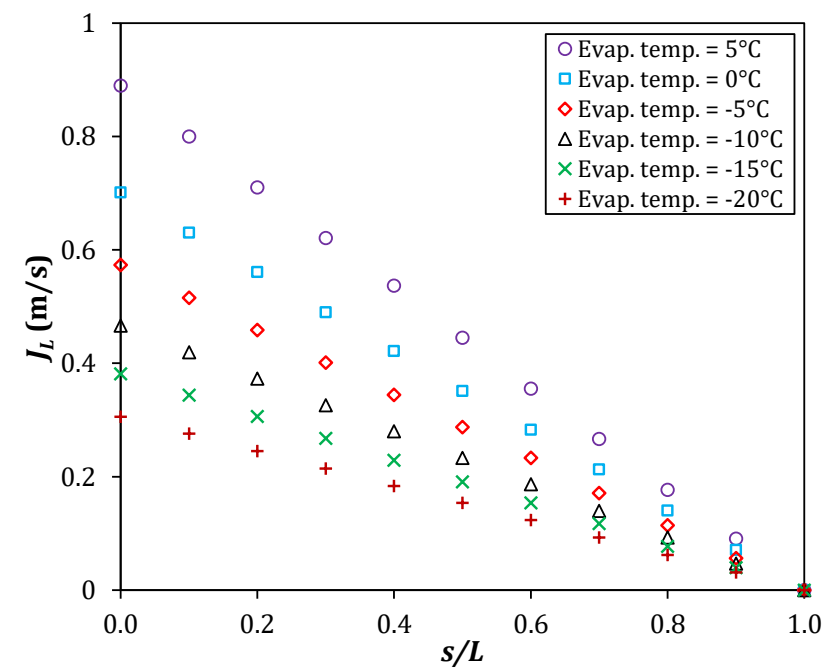

Fig. 5. Effect of axial position at evaporator pipe $(s / L)$ on superficial liquid velocity (cooling capacity 5.28 $\mathrm{kW}$ and pipe diameter $5 / 16$ in)

\subsection{Effect of Superficial Velocity on Flow Pattern}

The superficial vapor and liquid velocity data for the air conditioning machine with a cooling capacity of $2.64 \mathrm{~kW}$ are plotted into the flow-pattern map by Mandhane as shown in Figure 6 and Figure 7. These figures show the flow pattern of refrigerant in the evaporator pipe diameter of $3 / 8$ in. and $5 / 16$ in. with evaporating temperature variation from $-20^{\circ} \mathrm{C}$ to $+5^{\circ} \mathrm{C}$. In Figure 6 , it is shown that most of flow patterns for pipe diameter of $3 / 18$ in. are slug and wavy. The slug flow is obtained 
for superficial liquid velocity higher than $0.1 \mathrm{~m} / \mathrm{s}$. Meanwhile, the wavy flow is obtained when the superficial liquid velocity is lower than $0.1 \mathrm{~m} / \mathrm{s}$. Only two points indicate the annular flow, i.e., for evaporating temperature of $-20^{\circ} \mathrm{C}$ and superficial vapor velocity of 11.1 and $12.3 \mathrm{~m} / \mathrm{s}$ combined with superficial liquid velocity of 0.11 and $0.08 \mathrm{~m} / \mathrm{s}$.

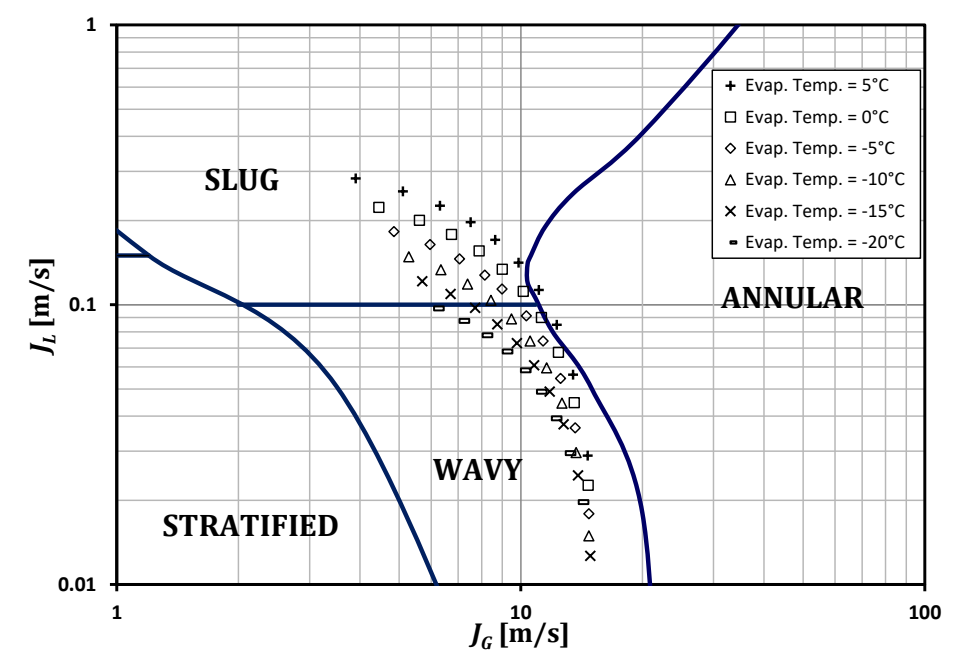

Fig. 6. Flow pattern in evaporator for cooling capacity of $2.64 \mathrm{~kW}$ and pipe diameter of $3 / 8$ in

For pipe diameter of 5/16 in., the wavy flow vanishes, and the annular flow appears in various operating conditions (Figure 7). For evaporating temperature of $+5^{\circ} \mathrm{C}$, the gas superficial velocity ranges from $6.13 \mathrm{~m} / \mathrm{s}$ to $24.93 \mathrm{~m} / \mathrm{s}$ while the superficial liquid velocity ranges from 0 to $0.44 \mathrm{~m} / \mathrm{s}$. Annular flow is found at $J_{G}>15.53 \mathrm{~m} / \mathrm{s}$.

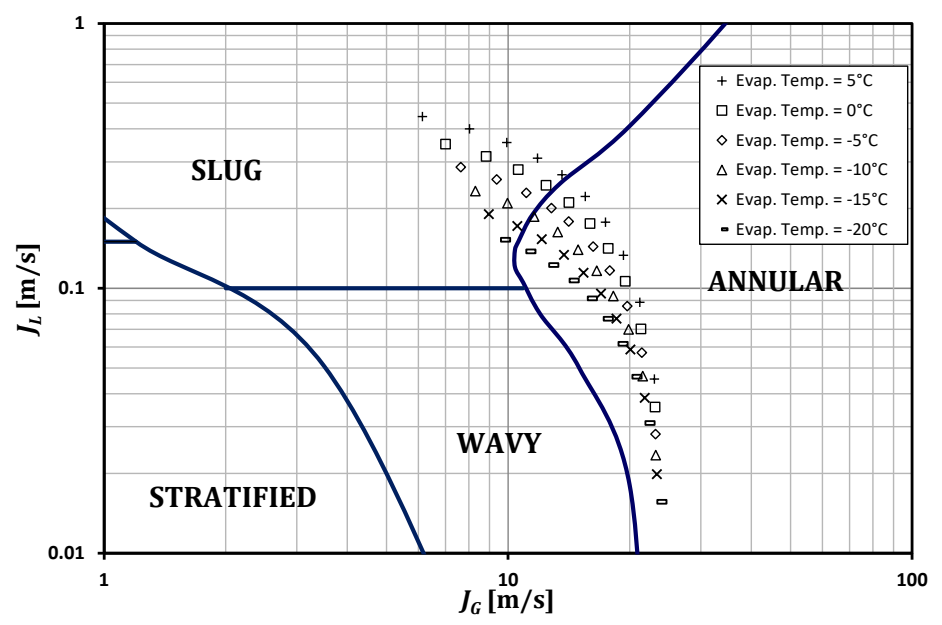

Fig. 7. Flow pattern in evaporator for cooling capacity of $2.64 \mathrm{~kW}$ and pipe diameter of $5 / 16$ in

For evaporating temperature of $+5^{\circ} \mathrm{C}$, the slug flow appears at the inlet of evaporator $(s / L=0)$ to $s / L=0.4$. The flow changes to annular flow at $s / L=0.5$ to the end of evaporator length $(s / L=1)$. For the lowest evaporating temperature $\left(-20^{\circ} \mathrm{C}\right)$, the slug flow only appears at the evaporator inlet. Starting from $s / L=0.1$ to the outlet of evaporator, the flow pattern is annular. Detailed examination of Figure 7 reveals that 49 points are in annular flow regime and the remaining 17 points are in the slug flow regime. 
For the nominal cooling capacity of $3.52 \mathrm{~kW}$, the larger pipe gives the vapor superficial velocity range of 5.52 to $19.86 \mathrm{~m} / \mathrm{s}$. Meanwhile, the superficial velocity of liquid refrigerant is in the range of 0 to $0.38 \mathrm{~m} / \mathrm{s}$. The plot of both phase velocities in the Mandhane map is presented in Figure 8 . Under this condition, the number of points located in the annular flow regime is 38 . The remaining are 17 points in the slug flow regime and 7 points are in the wavy flow regime. It means that the dominant flow regime for these operating conditions is annular flow, especially for low evaporating temperature. Detailed inspection of Figure 8 reveals that the annular flow pattern for the evaporating temperature of $-20^{\circ} \mathrm{C}$ starts at the axial position of $s / L=0.2$ or $1 / 5$ length of the evaporator. In contrast, for evaporating temperature of $+5^{\circ} \mathrm{C}$ the annular flow starts at $s / L=0.5$. It means that the annular flow is developed at half length of the evaporator. For $s / L<0.5$, the refrigerant is in the slug flow pattern. The wavy flow regime is found at near the outlet of the evaporator, i.e., at $s / L=0.9$ to 1.

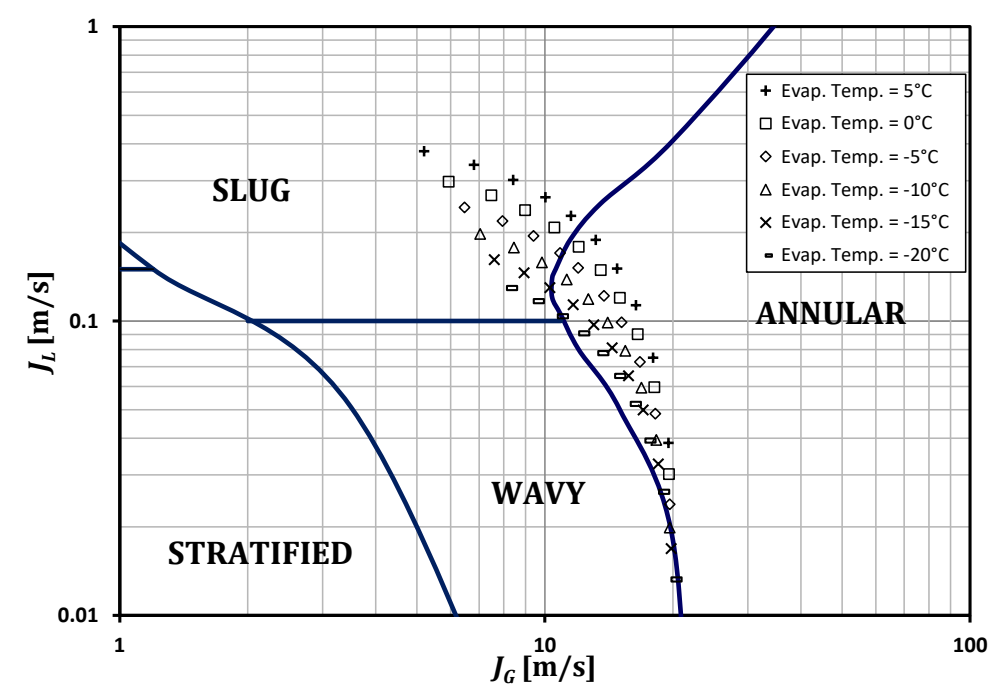

Fig. 8. Flow pattern in evaporator for cooling capacity of 3.52 $\mathrm{kW}$ and pipe diameter of $3 / 8$ in

The plot of vapor and liquid superficial velocity in the Mandhane map for pipe diameter 5/16 in. is presented in Figure 9. In this condition, the vapor superficial velocity ranges from 8.18 to 31.22 $\mathrm{m} / \mathrm{s}$, while that of the liquid ranges from 0 to $0.59 \mathrm{~m} / \mathrm{s}$. Both phase velocities are higher than that of the situation when the pipe diameter is $3 / 8$ in as the pipe diameter used is smaller. This smaller diameter gives the Out of 66 points investigated, 51 points are in annular flow regime, 13 are slug, and 2 are transition of slug-annular flow. Comprehensive examination of Figure 9 reveals that for evaporating temperature of $-20^{\circ} \mathrm{C}$, the flow pattern of refrigerant in the evaporator is all annular from $s / L=0$ to $s / L=1$. As the evaporating temperature increases, the portion of annular flow decreases. At the evaporating temperature of $-15^{\circ} \mathrm{C}$, for instance, the annular flow starts at the axial position of $s / L=0.1$, while at evaporating temperature of $+5^{\circ} \mathrm{C}$, the annular flow starts at $s / L=0.4$. As shown in Figure 9 and Figure 10, the superficial velocity is inversely proportional to the square diameter of pipe. This is caused by the constant mass flow rate of refrigerant along the refrigeration circuit when the cooling capacity is constant. 


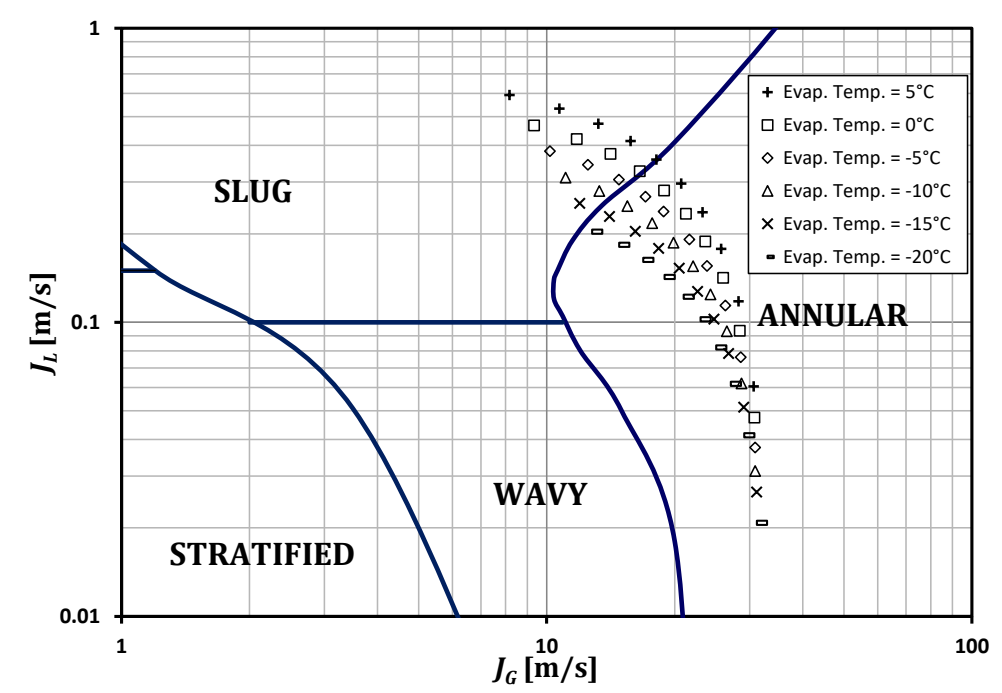

Fig. 9. Flow pattern in evaporator for cooling capacity of 3.52 $\mathrm{kW}$ and pipe diameter of $5 / 16$ in

For the largest cooling capacity $(5.28 \mathrm{~kW})$, the plot of $J_{G}$ vs $J_{L}$ in the Mandhane map for the evaporator pipe diameter of $3 / 8$ in is shown in Figure 10 . The range of $J_{G}$ for this case is $7.8 \mathrm{~m} / \mathrm{s}$ to $31.78 \mathrm{~m} / \mathrm{s}$, while that for $J_{L}$ is 0 to $0.57 \mathrm{~m} / \mathrm{s}$. The lowest $J_{G}$ is obtained for the highest evaporating temperature at the evaporator inlet $(s / L=0)$. On the other hand, the highest $J_{G}$ is found at the lowest evaporating temperature at the outlet of evaporator $(s / L=1)$. The different situation is shown by $J_{L}$, in which the highest value is provided at the highest evaporating temperature, while the lowest is given by the lowest evaporating temperature. This is mainly due to the lower vapor quality in the evaporator for the higher evaporating temperature. From the plot, it is apparent that for all evaporating temperatures, most of the flow pattern is annular $(78.8 \%)$ and the remaining $(21.2 \%)$ is slug. This result is in accordance with the experiment by flow visualization using R32, in which annular flow occurs at high gas velocity [16].

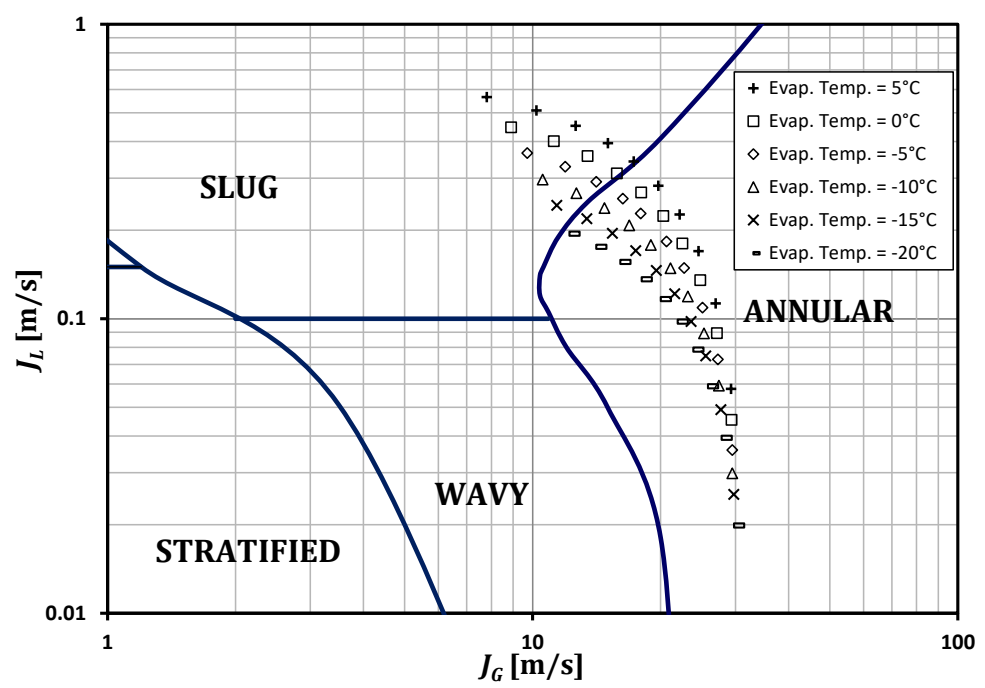

Fig. 10. Flow pattern in evaporator for cooling capacity of 5.28 $\mathrm{kW}$ and pipe diameter of $3 / 8$ in 
Decreasing the evaporator pipe diameter to 5/16 in. gives the similar results. In the later data, $83.3 \%$ of data points are located in annular flow region, while the remaining data points (16.7\%) are in the slug flow region (Figure 11). The annular flow covers all evaporating temperature settings, while the slug is found for evaporating temperature of $-15^{\circ} \mathrm{C},-10^{\circ} \mathrm{C},-5^{\circ} \mathrm{C}, 0^{\circ} \mathrm{C}$, and $5^{\circ} \mathrm{C}$. For the lowest evaporating temperature $\left(-20^{\circ} \mathrm{C}\right)$, neither wavy nor stratified flow patterns are found. As the pipe diameter decreases, the vapor superficial velocity increases to the range of $12.27 \mathrm{~m} / \mathrm{s}$ to $49.98 \mathrm{~m} / \mathrm{s}$. On the other hand, the range of liquid superficial velocity decreases to the range of 0 to $0.38 \mathrm{~m} / \mathrm{s}$. The dominant annular flow regime was confirmed by an experiment and simulation using an air conditioning machine of $5 \mathrm{~kW}$ capacity with R22 [17]. For constant evaporating temperature, the mass flow rate is proportional to the cooling capacity. Consequently, the vapor and liquid superficial velocities of refrigerant are also directly proportional to the cooling capacity of the air conditioning unit.

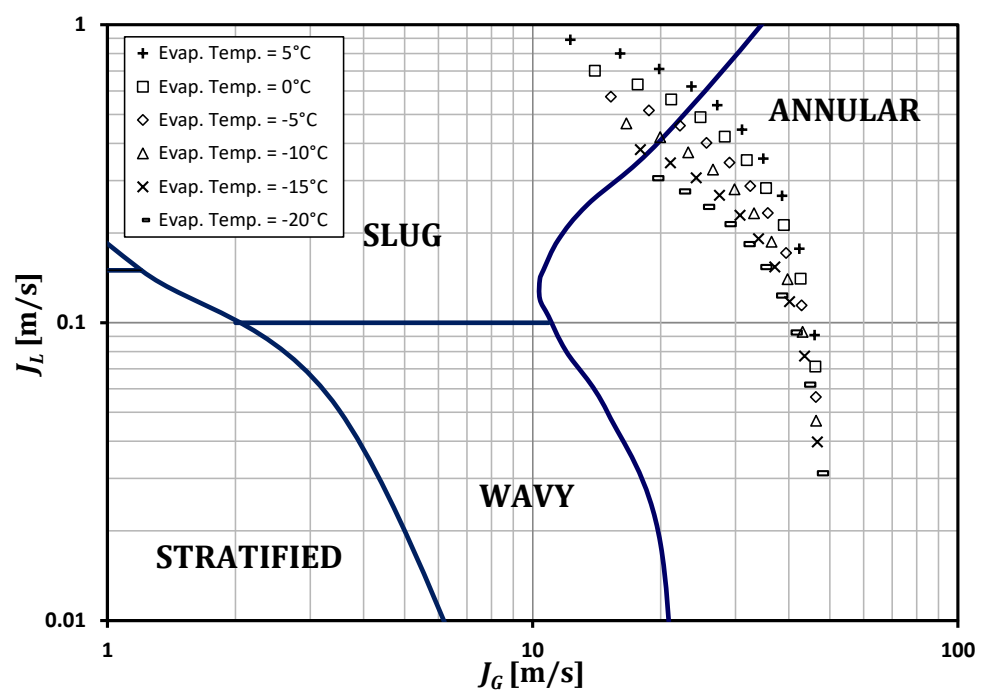

Fig. 11. Flow pattern in evaporator for cooling capacity of 5.28 $\mathrm{kW}$ and pipe diameter of 5/16 in

\subsection{Vapor and Liquid Superficial Velocity}

Due to the increase of the void fraction of refrigerant as it travels along evaporator pipe, the velocity of vapor refrigerant also increases. As a result, the superficial velocity of vapor refrigerant $\left(J_{G}\right)$ also increases. As could be seen in Figure 4, for evaporating temperature of $5^{\circ} \mathrm{C}$ the superficial vapor velocity increases linearly from $5.76 \mathrm{~m} / \mathrm{s}$ to $23.6 \mathrm{~m} / \mathrm{s}$ during travels from $\mathrm{s} / L=0$ to $\mathrm{s} / L=1$. Detailed examination of this figure reveals that the higher superficial velocity is resulted for the lower evaporating temperature. At the evaporator outlet, however, the superficial velocity of vapor refrigerant is equal even though the evaporating temperature is different. This is mainly due to the equal swept volume of the compressor used in the air conditioning machine and all refrigerant is in the vapor phase.

Apart from superficial vapor velocity, the superficial liquid velocity $\left(J_{L}\right)$ decreases as the refrigerant travels from the inlet to the outlet of the evaporator. This is mainly due to the reduced amount of liquid refrigerant when it travels along the evaporator pipe. For the cooling capacity of $5.28 \mathrm{~kW}$, at the inlet of evaporator the superficial liquid velocity ranges from $0.31 \mathrm{~m} / \mathrm{s}$ to $0.89 \mathrm{~m} / \mathrm{s}$. Examination of Figure 5 reveals that the superficial liquid velocity decreases as the evaporating temperature decreases. In addition, the superficial liquid velocity at the evaporator outlet is 0 because no liquid refrigerant remained, and all refrigerant is in the vapor phase. Along the 
evaporator, the evaporation rate of the refrigerant is likely to be linear function of evaporator segment length $(s / L)$. The behavior of superficial liquid velocity is similar for different evaporator pipe diameter, except that the value of the velocity is somewhat different. If the pipe diameter is larger, the superficial velocity will be smaller. As an example, for evaporator pipe diameter of $3 / 8$ inch, the value of $J_{L}$ at the evaporator inlet ranges from $0.19 \mathrm{~m} / \mathrm{s}$ to $0.57 \mathrm{~m} / \mathrm{s}$ for evaporating temperature of $-20^{\circ} \mathrm{C}$ to $5^{\circ} \mathrm{C}$.

\section{Conclusions}

Analysis on the behavior of void fraction and flow pattern of refrigerant R290 in a horizontal evaporator has been carried out under different evaporating temperature, different cooling capacity, and different pipe diameter. In general, the parameter reaches its maximum value at the evaporator outlet. For the lower evaporating temperature, the higher void fraction is resulted due to the lower refrigerant density. Lower evaporating temperature also provides the higher gas superficial velocity and lower liquid superficial velocity. At the evaporator outlet, the gas superficial velocity will be maximum, and the liquid superficial velocity will be minimum.

For the larger evaporator pipe diameter ( $3 / 8$ in) and lowest cooling capacity ( $2.64 \mathrm{~kW}$ ), wavy flow is dominant and annular flow is only found in $3 \%$ of pipe segment. The portion of annular flow increases to $57.6 \%$ and $78.8 \%$ for the cooling capacity of $3.62 \mathrm{~kW}$ and $5.28 \mathrm{~kW}$, respectively. The portion of slug flow is in the range of $21.2 \%$ to $33.3 \%$.

For the smaller evaporator pipe diameter (5/16 in), annular flow is dominant for all cooling capacity studied. The portion of annular flow is $74.2 \%, 80.3 \%$, and $83.3 \%$ for cooling capacity of 2.64 $\mathrm{kW}, 3.62 \mathrm{~kW}$, and $5.28 \mathrm{~kW}$, respectively. The slug flow occupies $16.7 \%$ to $25.8 \%$ of the pipe segment. In addition, the wavy flow does not appear for the smaller evaporator diameter.

\section{Acknowledgement}

The authors would thank to the (1) Ministry of Education and Culture the Republic of Indonesia, (2) Ministry of Research and Technology/National Research and Innovation Agency of the Republic of Indonesia, and (3) Politeknik Negeri Bandung for the kind supports during the preparation of this paper.

\section{References}

[1] Chisholm, D. "Pressure gradients due to friction during the flow of evaporating two-phase mixtures in smooth tubes and channels." International Journal of Heat and Mass Transfer 16, no. 2 (1973): 347-358. https://doi.org/10.1016/0017-9310(73)90063-X

[2] Spedding, P. L., and J. J. J. Chen. "Holdup in two phase flow." International Journal of Multiphase Flow 10, no. 3 (1984): 307-339. https://doi.org/10.1016/0301-9322(84)90024-7

[3] Hamersma, P. J., and J. Hart. "A pressure drop correlation for gas/liquid pipe flow with a small liquid holdup." Chemical Engineering Science 42, no. 5 (1987): 1187-1196. https://doi.org/10.1016/0009-2509(87)80068-4

[4] Cioncolini, Andrea, and John R. Thome. "Void fraction prediction in annular two-phase flow." International Journal of Multiphase Flow 43 (2012): 72-84. https://doi.org/10.1016/i.ijmultiphaseflow.2012.03.003

[5] Spedding, P. L., and D. R. Spence. "Prediction of holdup in two phase flow." International Journal of Engineering Fluid Mechanics 2 (1989): 109-118.

[6] Hart, J., P. J. Hamersma, and J. M. H. Fortuin. "Correlations predicting frictional pressure drop and liquid holdup during horizontal gas-liquid pipe flow with a small liquid holdup." International Journal of Multiphase Flow 15, no. 6 (1989): 947-964. https://doi.org/10.1016/0301-9322(89)90023-2

[7] Woldesemayat, Melkamu A., and Afshin J. Ghajar. "Comparison of void fraction correlations for different flow patterns in horizontal and upward inclined pipes." International Journal of Multiphase Flow 33, no. 4 (2007): $347-$ 370. https://doi.org/10.1016/j.ijmultiphaseflow.2006.09.004 
[8] Ma, Xiaokui, Guoliang Ding, Ping Zhang, Weizhe Han, Shinichi Kasahara, and Takahiro Yamaguchi. "Experimental validation of void fraction models for R410A air conditioners." International Journal of Refrigeration 32, no. 5 (2009): 780-790. https://doi.org/10.1016/j.ijrefrig.2008.12.009

[9] Setyawan, Andriyanto, Indarto Indarto, and Deendarlianto Deendarlianto. "Simplified Correlation for Liquid Holdup in a Horizontal TwoPhase Gas-Liquid Annular Flow." Journal of Advanced Research in Fluid Mechanics and Thermal Sciences 62, no. 1 (2019): 20-30.

[10] Nino, Victor German, P. S. Hrnjak, and T. A. Newell. Characterization of two-phase flow in microchannels. Air Conditioning and Refrigeration Center. College of Engineering. University of Illinois at Urbana-Champaign., 2002.

[11] Tu, Xiao, and P. S. Hrnjak. Flow and heat transfer in microchannels 30 to 300 microns in hydraulic diameter. Air Conditioning and Refrigeration Center. College of Engineering. University of Illinois at Urbana-Champaign., 2004.

[12] Ong, Chin L., and John R. Thome. "Flow boiling heat transfer of R134a, R236fa and R245fa in a horizontal $1.030 \mathrm{~mm}$ circular channel." Experimental Thermal and Fluid Science 33, no. 4 (2009): 651-663. https://doi.org/10.1016/i.expthermflusci.2009.01.002

[13] Zürcher, Olivier, D. Favrat, and J. R. Thome. "Evaporation of refrigerants in a horizontal tube: an improved flow pattern dependent heat transfer model compared to ammonia data." International Journal of Heat and Mass Transfer 45, no. 2 (2002): 303-317. https://doi.org/10.1016/S0017-9310(01)00145-4

[14] Tuo, Hanfei, and Pega Hrnjak. "Visualization and measurement of periodic reverse flow and boiling fluctuations in a microchannel evaporator of an air-conditioning system." International Journal of Heat and Mass Transfer 71 (2014): 639-652. https://doi.org/10.1016/i.ijheatmasstransfer.2013.10.024

[15] Li, Huize, and Pega Hrnjak. "Visualization and measurement of reverse flow in an actual channel of a microchannel evaporator." International Journal of Heat and Mass Transfer 108 (2017): 2346-2354. https://doi.org/10.1016/i.ijheatmasstransfer.2017.01.085

[16] Li, Houpei, and Pega Hrnjak. "Flow visualization of R32 in parallel-port microchannel tube." International Journal of Heat and Mass Transfer 128 (2019): 1-11. https://doi.org/10.1016/j.ijheatmasstransfer.2018.08.120

[17] Tong, Lige, Haiyan Li, Li Wang, Xinxing Sun, and Yunfei Xie. "The effect of evaporator operating parameters on the flow patterns inside horizontal pipes." Journal of Thermal Science 20, no. 4 (2011): 324-331. https://doi.org/10.1007/s11630-011-0477-2

[18] Setyawan, Andriyanto, Deendarlianto, Indarto, and Fredrick Neo. "Experimental investigation on liquid film asymmetry in air-water horizontal annular flow." In AIP Conference Proceedings, vol. 1737, no. 1, p. 040009. AIP Publishing LLC, 2016. https://doi.org/10.1063/1.4949297

[19] Qian, Hongliang, and Pega Hrnjak. "Void fraction measurement and flow regimes visualization of R134a in horizontal and vertical ID $7 \mathrm{~mm}$ circular tubes." International Journal of Refrigeration 103 (2019): 191-203. https://doi.org/10.1016/j.ijrefrig.2019.04.018

[20] Akbar, R., Pamitran, A. S., \& Oh, J. T. (2021). "Two-Phase Flow Boiling Heat Transfer Coefficient with R290 in Horizontal $3 \mathrm{~mm}$ Diameter Mini Channel." Journal of Advanced Research in Experimental Fluid Mechanics and Heat Transfer 3, no. 1 (2021): 1-8.

[21] Setyawan, Andriyanto, Indarto, and Deendarlianto. "Measurement of liquid holdup by using conductance probe sensor in horizontal annular flow." Journal of Advanced Research in Fluid Mechanics and Thermal Sciences 53, no. 1 (2019): 11-24.

[22] Mandhane, J. M., G. A. Gregory, and K. Aziz. "A flow pattern map for gas-liquid flow in horizontal pipes." International Journal of Multiphase Flow 1, no. 4 (1974): 537-553. https://doi.org/10.1016/0301-9322(74)90006-8

[23] Setyawan, Andriyanto. "Effects Of Evaporating Temperature on Flow Pattern in A Horizontal Evaporator." Frontiers in Heat and Mass Transfer (FHMT) 14, no. 22 (2020). https://doi.org/10.5098/hmt.14.22

[24] Tritjahjono, Rachmad Imbang, Kasni Sumeru, Andriyanto Setyawan, and Mohamad Firdaus Sukri. "Evaluation of subcooling with liquid-suction heat exchanger on the performance of air conditioning system using R22/R410A/R290/R32 as refrigerants." Journal of Advanced Research in Fluid Mechanics and Thermal Sciences 55, no. 1 (2019): 1-11. 